\title{
GESTÃO INTEGRADA DE RESÍDUOS SÓLIDOS URBANOS NO MUNICÍPIO DE BELÉM, PARÁ, BRASIL: VANTAGENS E DESAFIOS DA SUA IMPLEMENTAÇÃO
}

Emile Lebrego Cardoso

emilelebrego@gmail.com

Universidade do Estado do Pará -

UEPA, Belém, Pará, Brasil.

\section{Hélio Raymundo Ferreira}

Filho

helio.ferreira@uepa.br

Universidade do Estado do Pará -

UEPA, Belém, Pará, Brasil.

\section{Vanusa Carla Pereira Santos}

vanusasantos18@yahoo.com.br Universidade Federal do Pará UFPA, Belém, Pará, Brasil.

\section{Aline de Oliveira Ferreira} line.ferreira@uepa.br

Universidade do Estado do Pará UEPA, Belém, Pará, Brasil.

\section{RESUMO}

O presente trabalho tem como objetivo descrever a gestão dos resíduos sólidos urbanos (RSU) na cidade de Belém, Pará, Brasil, explanando as vantagens e os desafios da implementação de uma gestão integrada. Para isso, fez-se um levantamento bibliográfico em periódicos recentes que abordam a temática, além de uma análise documental do Plano Estadual de Gestão Integrada de Resíduos Sólidos do estado do Pará. Em adição, foram realizadas entrevistas semiestruturadas, entre agosto e novembro de 2018, com representantes da gestão de resíduos nos níveis estadual e municipal, buscando informações sobre a forma de gestão adotada e as dificuldades enfrentadas, coletando, assim, dados primários e secundários. As informações reunidas demonstram que a gestão dos RSU em Belém apresenta falhas, uma vez que o município não conta com um plano de gestão integrada capaz de agregar informações relevantes para a formulação de programas e ações necessárias para minimizar os problemas proporcionados pela alta geração de resíduos e sua disposição final. Os resultados apresentados são de grande importância por proporcionar uma discussão mais detalhada e voltada à gestão dos resíduos em Belém, reforçando as exigências da Política Nacional de Resíduos Sólidos quanto à forma financeira e ambientalmente sustentável de realizar essa gestão.

Palavras-chave: Economia ambiental; Reciclagem; Resíduos Sólidos Urbanos; Gestão orçamentária; Meio ambiente. 


\section{INTRODUÇÃO}

A revolução tecnológica experimentada desde o advento da Revolução Industrial, no século XVIII, culminou em novas relações homem-homem e homem-natureza, aumento da industrialização, produção, consumo, desenvolvimento econômico, e tem provocado diversos impactos ambientais. A exploração desenfreada dos recursos naturais, o consumo intensificado de produtos, o aumento populacional, a urbanização, o crescimento e o desenvolvimento econômico e industrial agravam o montante de resíduos sólidos urbanos (RSU) despejados indevidamente no meio ambiente (Costa et al., 2018; Dias, 2012; Viveiros et al., 2015).

O descarte, o manejo correto e a coleta seletiva de RSU são questões de difícil solução para a sociedade e, no que diz respeito ao Brasil, tornaram-se um grave problema sanitário, ambiental, social e de saúde pública (Berticelli e Korf 2016; Jacobi e Besen, 2011; Santiago e Dias, 2012). Nesse sentido, são diversos os problemas decorrentes do aumento da geração de RSU, tais como os custos para coleta e tratamento, a dificuldade de encontrar um lugar adequado para sua disposição final, a degradação do solo, a contaminação do lençol freático e o desperdício de matérias-primas (Conde, et al., 2014).

Atualmente, essa temática é um desafio para a gestão das cidades rumo à sustentabilidade. Visando à melhoria de problemas relacionados à geração, ao manejo e ao despejo de RSU, a gestão desses processos deve ser realizada de forma integrada, abrangendo os aspectos socioambientais e comportamentais (Berticelli e Korf, 2016; Neves, 2013; Dias, 2012).

Um marco regulatório para os resíduos sólidos no Brasil foi a Lei no 12.305, de 2 de agosto de 2010, criando a Política Nacional de Resíduos Sólidos (PNRS) que, a partir de suas diretrizes, estabeleceu o conteúdo mínimo necessário para a criação do Plano Estadual de Gestão Integrada de Resíduos Sólidos (PEGIRS) de cada unidade federativa. Com a criação do PEGIRS, também por meio de suas diretrizes, cada município se torna responsável por criar seu próprio Plano Municipal de Gestão Integrada de Resíduos Sólidos (PMGIRS). A partir da criação destes planos, estaduais e municipais, é possível a arrecadação de recursos financeiros provenientes da União, os quais são necessários para a execução de programas, ações de limpeza urbana, manejo dos resíduos e empreendimentos de coleta seletiva (Brasil, 2010; Machado, 2012; Estado do Pará, 2014).

A PNRS define que os RSU devem seguir a linha de prevenção, redução, reutilização, reciclagem, tratamento e disposição ambientalmente adequada em aterros sanitários com o devido planejamento e monitoramento, além de abordar os conceitos de responsabilidade compartilhada, que englobam a logística reversa, defendem a capacitação e a valorização dos catadores de materiais recicláveis, bem como a sua inserção no processo de gestão desses resíduos estabelecendo uma integração social, definindo a importância da responsabilidade compartilhada, da gestão dos recrussos naturais por meio da responsabilidade social na gestão de resíduos, a compostagem e a geração de energia. Ademais, hierarquiza o manejo e o despejo, diferenciando rejeito de resíduo e valorizando a recuperação de materiais recicláveis (Jacobi e Besen, 2011; Dias, 2012; Santiago e Dias, 2012; Machado, 2012; Neves, 2013; Estado do Pará, 2014; Berticelli e Korf, 2016).

De acordo com Neves (2013) e Santiago e Dias (2012), a PNRS surge como uma ferramenta para orientar o planejamento e a normatização da gestão de resíduos. Tal gestão deve ser realizada de forma integrada entre todos os entes federativos, governamentais, estaduais e municipais, sendo capaz de gestar adequadamente os resíduos de forma colaborativa e participativa, coletando desde estimativas municipais até informações de ordem estadual, compreendendo ações voltadas para a busca de soluções relacionadas à problemática dos RSU que beneficiarão a todos, e considerando a previsão da PNRS de que esses problemas devem ser solucionados e/ou minimizados a partir de uma gestão integrada. Esse sistema de gestão integrada é complexo, pois precisa contemplar questões relacionadas ao ciclo de vida do produto, minimizando o uso de recursos naturais, visando à não geração de resíduos e, assim, colaborando para que não haja sobrecarga dos aterros, de modo a aproveitá-los ao máximo possível e realocar os resíduos passíveis de reaproveitamento para centros de triagem de materiais recicláveis (Neves, 2013; Estado do Pará, 2014).

Nesse contexto, este artigo tem como objetivo descrever como é feita a gestão de RSU na cidade de Belém, explanando as vantagens e os desafios da implementação de uma gestão integrada de resíduos sólidos. Como metodologia, utilizou-se a técnica de pesquisa mista, coletando e analisando dados quantitativos referentes à geração e à disposição de RSU, bem como dados qualitativos, obtidos por meio de revisão bibliográfica, análise documental e estudo de caso.

De início, expõem-se o modelo de gestão de RSU adotado pelo estado do Pará, comparando a quantidade gerada de RSU do estado com o montante gerado pela região Norte do Brasil e a variação da geração destes resíduos no nível nacional, nos anos de 2014, 2017 e 2018. Em seguida, é analisado o modelo de gestão de RSU adotado pelo estado do Pará por meio do PEGIRS. Por fim, discute-se o estudo de caso específico de Belém, apontando os motivos pelos quais a gestão de RSU no município é deficitária e como uma gestão integrada de resíduos é importante para que os problemas alusivos à geração e à disposição destes sejam minimizados. 


\section{METÓDO}

A pesquisa discutida aqui é de natureza mista, qualitativa e exploratória. Baseia-se principalmente na "percepção e compreensão humana" (Stake, 2011, p. 21) e realiza-se a partir de revisão bibliográfica sobre o tema abordado e análise documental das informações presentes no PEGIRS do estado do Pará, propondo estudar a questão dos resíduos sólidos, sua gestão e problemática, utilizando, então, dados primários e secundários para a realização da pesquisa.

\section{Área de estudo}

Belém é a capital do estado do Pará, município-polo da Regiões de Integração (RI) Metropolitana, com população estimada, em 2019, de 1.492.745 pessoas, e renda per capita de $\mathrm{R} \$ 20.821,46$, em 2017. A área do município compreende 1.059,466 $\mathrm{Km}^{2}$, abrangendo 71 bairros. Em 2010, $67,9 \%$ dos domicílios possuía esgotamento sanitário adequado e $36,1 \%$ das vias públicas eram urbanizadas, com calçadas e pavimentação adequadas (IBGE, 2020).

\section{Geração de resíduos sólidos urbanos no Pará}

A análise da geração de RSU foi feita a partir das informações das RI dos municípios do Pará, as quais permitiram que o levantamento de dados fosse mais eficaz. Tal método foi utilizado para o levantamento da quantidade diária de RSU produzida por cada RI de acordo com a sua população. Atenta-se para a RI metropolitana (atualmente RI Guajará), que abrange Belém como município-polo e para os demais municípios pertencentes à Região Metropolitana de Belém (RMB): Ananindeua, Benevides, Marituba, Santa Bárbara do Pará e Santa Isabel do Pará (figura 1) (Estado do Pará, 2014).

A tabela 1 refere-se a dados coletados no PEGIRS do estado do Pará a respeito da quantidade diária em toneladas de geração de RSU, demonstrando a participação da RI Metropolitana.

Tabela 1. RSU total (toneladas/dia) 2014

\begin{tabular}{|c|c|}
\hline Região & RSU total (toneladas/dia) \\
\hline RI Metropolitana & 1.902 \\
\hline Pará & 4.507 \\
\hline
\end{tabular}

Fonte: Elaborado a partir de Estado do Pará (2014)
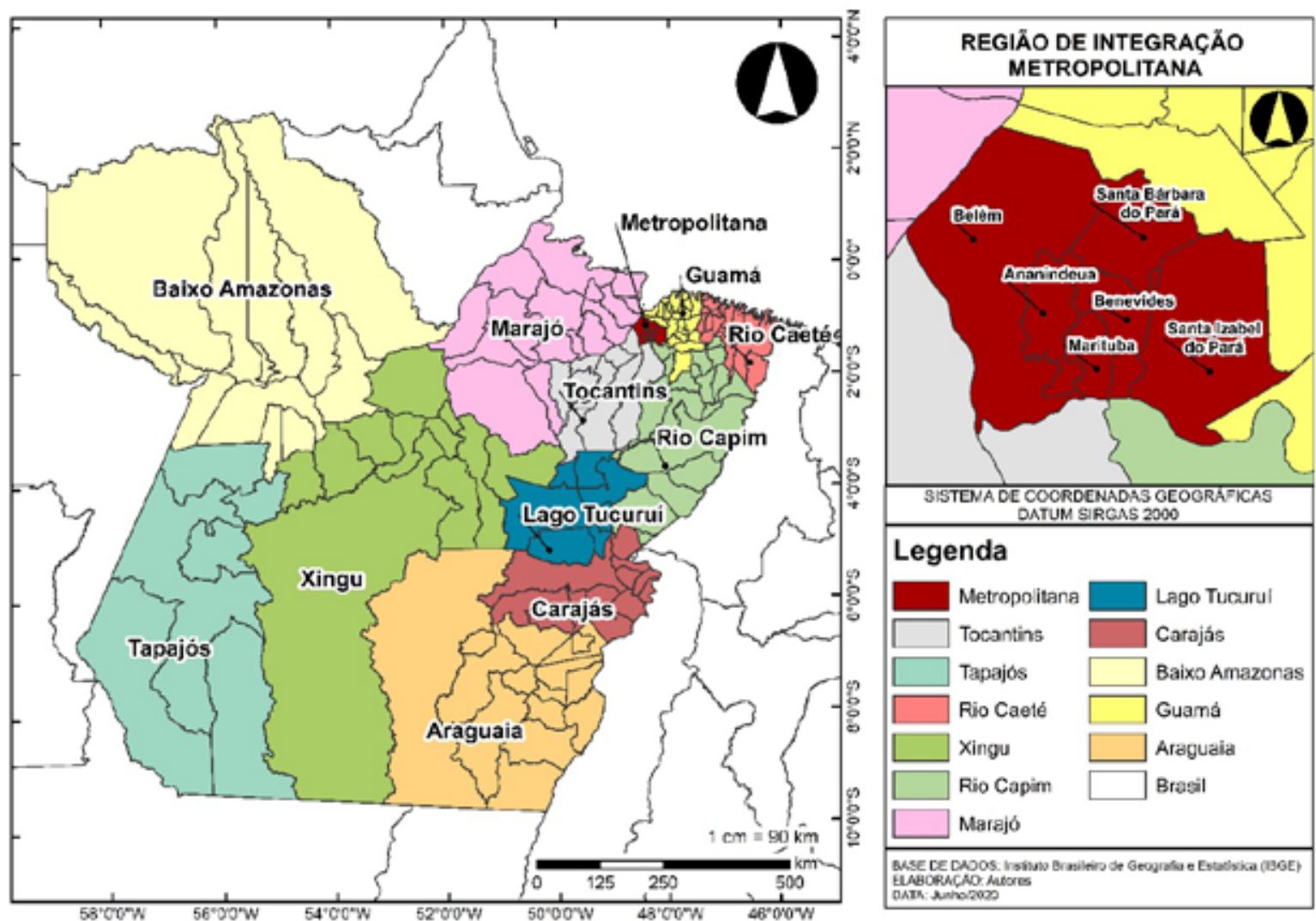

Figura 1. Regiões de Integração do Estado do Pará Fonte: Os próprios autores. 


\section{Gastos com a gestão de resíduos sólidos urbanos em Belém}

Na tabela 2 expõe-se os valores gastos pela prefeitura de Belém com a gestão dos RSU no município, no intervalo de 2016 a 2018. Estes valores coletados estão no portal da transparência da referida prefeitura, detalhando o valor gasto com a coleta, manejo e disposição final dos RSU em aterro sanitário, além do valor gasto com a estruturação de um galpão de triagem de coleta seletiva desativado.

Tabela 2. Gastos com a gestão de RSU pela prefeitura de Belém (2016-2018)

\begin{tabular}{|c|c|}
\hline Tipo de gasto & Valor (R\$) \\
\hline Coleta, manejo e disposição final & $370.623 .752,02$ \\
\hline $\begin{array}{c}\text { Galpão de triagem } \\
\text { de coleta seletiva desativado }\end{array}$ & $143.079,00$ \\
\hline
\end{tabular}

Fonte: Elaborado a partir do Portal da transparência prefeitura de Belém (2020)

A tabela 3 conta com dados primários coletados em entrevistas com os responsáveis pela gestão de RSU no município, identificando Belém como o município que mais encaminha resíduos para aterro sanitário.

Tabela 3. Disposição de RSU no aterro sanitário

\begin{tabular}{|c|c|}
\hline Região & (t/mês) \\
\hline Belém & 30.000 \\
\hline Ananindeua, Marituba & 10.000 \\
\hline Total & 40.000 \\
\hline
\end{tabular}

Fonte: Os próprios autores.

Além da perspectiva regional sobre a geração e gestão de RSU, são apresentados dados que representam os RSU e sua distribuição nacional quanto à geração e à destinação. Mobiliza, então, os dados coletados e analisados, concomitantemente, para dar suporte ao objetivo do trabalho de investigar as vantagens e os desafios da implementação de uma gestão integrada, perante a necessidade de uma gestão eficiente em face da crescente geração desses resíduos e da forma como são dispostos (Creswell, 2010; Freitas; Jabbour, 2011; Lima et al., 2012).

Conforme dados de 2020 disponibilizados pela Associação Brasileira de Empresas de Limpeza Pública e Resíduos Especiais (ABRELPE), a quantidade de RSU coletada no Brasil, no ano de 2018 , foi de 72,7 milhões de toneladas do montante de 79 milhões de toneladas geradas no ano. A distribuição conforme destinação dada à estes resíduos é exposta na tabela 4.
Tabela 4. Quantidade de RSU conforme sua destinação no ano de 2018

\begin{tabular}{|c|c|}
\hline Destinação & RSU milhões (t/ano) \\
\hline Aterros controlados e lixões & 29,5 \\
\hline Aterro sanitário & 43,3 \\
\hline Total coletado & 72,2 \\
\hline
\end{tabular}

Fonte: Adaptado de ABRELPE (2020)

Na tabela 5 são apresentados dados referentes ao índice de cobertura (coleta) de RSU no ano de 2018 conforme as regiões do Brasil. Verifica-se que a região Sudeste é a que mais coleta RSU, aproximadamente $98,07 \%$ do seu montante gerado por dia. Isso pode estar relacionado ao fato de que é também a região mais populosa do Brasil, com aproximadamente 88,37 milhões de habitantes (ABRELPE, 2020; IBGE, 2020).

Tabela 5. Quantidade de RSU coletada no ano de 2018

\begin{tabular}{|c|c|}
\hline Região & RSU (toneladas/dia) \\
\hline Norte & 13.069 \\
\hline Nordeste & 43.753 \\
\hline Centro-Oeste & 14.941 \\
\hline Sudeste & 105.977 \\
\hline Sul & 20.387 \\
\hline Brasil & 198.127 \\
\hline
\end{tabular}

Fonte: Adaptado de ABRELPE (2020)

A tabela 6 aborda a destinação dos RSU na região Norte do Brasil no ano de 2018, demonstrando a quantidade em toneladas/dia dos resíduos encaminhados para aterro controlado, aterro sanitário e lixão.

Tabela 6. Destinação RSU - região Norte no ano de 2018

\begin{tabular}{|c|c|}
\hline Destino & RSU (toneladas/dia) \\
\hline Aterro controlado e lixão & 8.456 \\
\hline Aterro sanitário & 7.617 \\
\hline
\end{tabular}

Fonte: Adaptado de ABRELPE (2020)

A estratégia de pesquisa escolhida para a sustentação do trabalho foi a realização de um estudo de caso que, de acordo com Lima et al. (2012), é adequado para investigar um determinado evento, processo ou conjunto de pessoas. 0 estudo de caso abordado foi a gestão dos RSU em Belém, com o objetivo de descrever o funcionamento e os problemas relacionados a ela, reunindo informações em visitas ao Departamento de Resíduos Sólidos (Dres), integrante da Secretaria Municipal de Saneamento (Sesan), responsável pela gestão de resíduos sólidos e pela coleta seletiva no município (Yin, 2015).

Para aprofundar os resultados, os dados quantitativos e qualitativos foram coletados concomitantemente, possibi- 
litando uma melhor interpretação da questão apresentada (Creswell, 2010). A justificativa da necessidade da adoção de uma gestão integrada de RSU é reforçada perante o montante de resíduos gerados nos níveis nacional, estadual e na RI Metropolitana.

\section{RESULTADOS E DISCUSSÃO}

\section{Gestão de resíduos sólidos urbanos no estado do Pará}

Em área, o Pará é o segundo maior estado federativo do Brasil, ocupando cerca de $15 \%$ do território nacional. Situado na região Norte, tem aproximadamente 1.247 .690 km², com 145 municípios separados em 12 RI, conforme o Decreto Estadual no 1.066, de 19 de junho de 2008, a fim de auxiliar a execução e o planejamento de políticas públicas. No estado, são geradas anualmente, em média, 1.646.055 toneladas totais de RSU, mas interessa aqui a provisão de geração diária fornecida pelo PEGIRS de 2014 (Estado do Pará, 2014).

Belém e os demais municípios da Região Metropolitana de Belém (RMB) fazem parte da RI Metropolitana (ou RI Guajará), sendo responsáveis pela geração de 1.902 toneladas/dia da produção de RSU, do total de 4.507 toneladas/ dia geradas no Pará em 2014, correspondendo a aproximadamente $19,20 \%$ da geração diária do estado. Dessa forma, Belém e a RMB têm uma participação expressiva no total de resíduos gerados pelo Pará, sendo pertinente analisar a forma como a gestão destes municípios acontece.

Na tabela 7 são apresentados dados da geração de RSU total em toneladas/dia. Em 2014, a região Norte teve 15.413 toneladas/dia, enquanto a geração total do Pará foi de 4.507 toneladas/dia, correspondendo a $29,24 \%$ da quantidade produzida pela região, ao passo que a RI metropolitana gerou 1.902 toneladas/dia de resíduos, representando $26,5 \%$ do total do estado.

Tabela 7. RSU total (toneladas/dia) 2014

\begin{tabular}{|c|c|}
\hline Região & RSU total (toneladas/dia) \\
\hline Norte & 15.413 \\
\hline Nordeste & 55.177 \\
\hline Centro-Oeste & 16.948 \\
\hline Sudeste & 102.431 \\
\hline Sul & 22.328 \\
\hline Brasil & 212.297 \\
\hline
\end{tabular}

Fonte: Adaptado de ABRELPE (2015)

Na Tabela 8 são apresentados os mesmos tipos de dados, agora de 2017. Na região Norte, a geração de RSU foi de 15.634 toneladas/dia. Verifica-se que, comparando 2014 e 2017, houve um aumento nos níveis estadual e nacional, o qual pode estar relacionado a fatores culturais, econômicos e sociais. Vale observar que a forma de como esses resíduos são gestionados e destinados também sofre interferência dessa elevação.

Tabela 8. RSU total (toneladas/dia) 2017

\begin{tabular}{|c|c|}
\hline Região & RSU total (toneladas/dia) \\
\hline Norte & 15.634 \\
\hline Nordeste & 55.492 \\
\hline Centro-Oeste & 15.519 \\
\hline Sudeste & 105.794 \\
\hline Sul & 21.327 \\
\hline Brasil & 213.766 \\
\hline
\end{tabular}

Fonte: Adaptado de ABRELPE (2018)

Comparando a tabela 6 com a tabela 7, a qual expressa os dados da geração de RSU no ano de 2018, verificou-se que houve um aumento pouco expressivo no total de resíduos gerados, entretanto, a coleta de RSU aumentou em 1,66\%, partindo de 196.050 mil de toneladas coletadas por dia para 199.311 mil.

Tabela 9. RSU (toneladas/dia) 2018

\begin{tabular}{|c|c|}
\hline Região & RSU total (toneladas/dia) \\
\hline Norte & 16.073 \\
\hline Nordeste & 53.975 \\
\hline Centro-Oeste & 15.932 \\
\hline Sudeste & 108.063 \\
\hline Sul & 21.561 \\
\hline Brasil & 216.629 \\
\hline
\end{tabular}

Fonte: Adaptado de ABRELPE (2020)

Conforme ABRELPE (2020), a região Norte apresenta o maior índice de RSU que são manejados para lixões. No ano de 2018 , o montante de RSU alcançou aproximadamente $35 \%$ (tabela 4) da quantidade gerada, sendo mais elevado do que as outras regiões do país. De acordo com Ribeiro e Mendes (2018), a quantidade gerada por uma determinada população é inconstante, variando conforme a renda, o modo de vida, a época do ano e o condicionamento das mercadorias. Portanto, é importante que haja uma gestão eficiente desses resíduos, que vêm aumentando com o passar dos anos, provocando problemas.

Conforme a PNRS, os planos de gestão integrada de RSU, sejam eles estaduais ou municipais, deverão estabelecer metas de não geração, redução, reutilização e reciclagem, para que a quantidade de rejeitos encaminhados aos aterros seja reduzida. Isso, porque muitos desses materiais que podem ser reciclados demandam um período para a sua decomposição e ao serem despejados nos aterros ocupam um espaço que poderia abrigar uma maior quantidade de rejeitos não recicláveis 
e orgânicos, colaborando também para a vida útil do aterro (Neves, 2013; Estado do Pará, 2014).

A PNRS foi criada em consonância com as já vigentes Política Nacional do Meio Ambiente (Lei $n^{\circ} 6.938$, de 31 de agosto de 1981), Política Nacional de Educação Ambiental (Lei no 9.795, de 27 de abril de 1999) e Política Federal de Saneamento Básico (Lei $n^{\circ} 11.445$, de 5 de janeiro de 2007). Porém, os planos não definem as formas de gerenciamento ou implementação de políticas públicas, dando apenas sustentação para que os municípios obtenham recursos financeiros da União para o gerenciamento dos resíduos e para que seja feita de forma integrada entre as secretarias estaduais e os órgãos municipais (Oliveira; Galvão Junior, 2016).

Um ponto importante abordado na PNRS é a responsabilidade compartilhada: os consumidores, fabricantes, importadores e distribuidores têm a obrigação de realizar um descarte adequado dos produtos, enquanto o setor público responsável deve garantir a limpeza pública e o manejo dos resíduos. Conforme o art. 6o da Lei $n$ o 12.305/2010, os consumidores devem acondicionar corretamente e de forma diferenciada os resíduos sólidos gerados, além de disponibilizar adequadamente os resíduos reutilizáveis e recicláveis para coleta ou devolução. Já o art. 70 define as responsabilidades do poder público, entre as quais a efetividade das ações voltadas para assegurar a observância da PNRS (Brasil, 2010; Machado, 2012; Neves, 2013; Estado do Pará, 2014).

O PEGIRS do Pará foi criado em 2014 pelo governo do estado em parceria com a Consultoria em Meio Ambiente Ltda. (Brencorp). Contém o diagnóstico consolidado que retrata a situação dos RSU no estado e nas $12 \mathrm{RI}$ mencionadas anteriormente. Esse diagnóstico foi importante para retratar a realidade dos municípios paraenses quanto à produção, ao manejo e à destinação de RSU, permitindo o levantamento de dados primários e secundários necessários para o desenvolvimento do plano, com a participação das secretarias dos municípios integrantes das RI e órgãos do governo do estado (Estado do Pará, 2014).

O PEGIRS tem como competência: coleta de informações sobre geração de RSU; coleta seletiva e sua implementação; destino final dos resíduos; municípios com aterros sanitários, lixões e aterros controlados; projetos de aterro sanitário no município-polo das Rl; sistema de recuperação de materiais recicláveis e existência de coleta seletiva, galpões de triagem no município-polo implantados ou projetados; estimativa ou censo dos catadores em situação de rua, associações, cooperativas ou lixões; PMGIRS, sua existência no município-polo e estado de sua elaboração; sustentabilidade financeira; existência de sistema de cobrança no município-polo referente aos serviços de coleta seletiva e destino final de RSU (Estado do Pará, 2014).
O órgão responsável pela elaboração de políticas públicas e planos de gerenciamento de resíduos sólidos no Pará é a Secretaria de Estado de Desenvolvimento Urbano e Obras Públicas (Sedop), enquanto a Secretaria de Meio Ambiente e Sustentabilidade (Semas) é o órgão fiscalizador da execução dos planos e das políticas públicas. De acordo com informações fornecidas pela Sedop, o estado do Pará está atrasado na implementação de políticas públicas de RSU e saneamento.

Conforme mencionado anteriormente, o plano estadual existe e em 2018 completou quatro anos. A PNRS decreta que todos os planos estaduais e municipais devem passar por análise e reavaliação do seu funcionamento de quatro em quatro anos, até alcançar o horizonte de 20 anos, quando são encaminhados para revisão (Brasil, 2010; Estado do Pará, 2014).

Um PEGIRS não é uma lei, mas sim um documento de caráter orientativo. É uma ferramenta de planejamento a partir da qual o estado estabelece um guia para o investimento em políticas públicas e ações referentes à gestão de resíduos - ainda não há no Pará uma lei específica para tratar do assunto. A lei é importante na gestão dos RSU, mas sua inexistência não impede que o plano seja elaborado ou executado.

A PNRS fornece as diretrizes necessárias para a elaboração do plano estadual, que, por sua vez, determina as macrodiretrizes que os municípios devem adotar para a criação dos seus planos de gestão integrada. Em Belém, o órgão responsável pelo plano é a Sesan. A questão da gestão e do manejo de RSU em Belém será abordada na próxima seção, que trata do já referido estudo de caso.

O plano é estruturado a partir do diagnóstico previamente realizado, que tem todas as informações demográficas, geográficas, socioeconômicas e físicas da região para a qual se destina, fornecendo instruções relevantes para a questão dos RSU, como a forma de coleta, o armazenamento, os tipos de resíduos e a quantidade de resíduos coletados. Após o diagnóstico, é feito o prognóstico, a partir do qual se apontam as possíveis soluções relativas aos problemas encontrados no diagnóstico e à elaboração de cenários futuros, definindo objetivos e metas a serem alcançados. A última etapa do plano diz respeito à sua essência e para que serve. É nela que se encontram as proposições, as diretrizes específicas, as diretrizes atingidas, as estratégias, os programas, os objetivos, os projetos e as ações (Berticelli; Korf, 2016; Estado do Pará, 2014).

O PEGIRS do Pará tem um consórcio para atender à demanda de investimento dos municípios, no qual a gestão do recurso fica sob responsabilidade do prefeito da cidade à qual se refere, organizando a logística dos resíduos destinados ao município-polo da RI oriundos dos outros municípios da RI e incentivando a ampliação dos serviços de coleta, implantação de um serviço de entrega e transferência de resíduos sólidos. Também estimula o fortalecimento da gestão pública dos resí- 
duos sólidos, auxiliando os municípios na elaboração de seus próprios planos inter-regionais para que esses recursos sejam destinados.

A PNRS foi um marco importante para a gestão e a adequação do manejo de todos os tipos de resíduos, em especial os RSU. É uma ferramenta necessária para que o estado crie seu plano regionalizado de gestão de resíduos e, assim, obtenha recursos da União que ajudarão nas ações e nos projetos referentes à gestão. A partir do plano estruturado pelo estado, cada município, contando também com suas características econômicas e sociais, elabora um plano de gestão de resíduos regionalizado capaz de fornecer informações valorosas para que a gestão seja feita de forma eficaz e integrada entre todos os entes federativos.

\section{Gestão de resíduos sólidos urbanos em Belém}

Entre as exigências da PNRS, estão a elaboração do PEGIRS e a implantação de aterros sanitários como solução ambientalmente correta para a destinação final dos resíduos gerados nas cidades. Atualmente, Belém dispõe do aterro sanitário Guamá Tratamento de Resíduos (GTR), gerenciado pela empresa Solvi (Soluções para a Vida), que tem 28 aterros sanitários espalhados pelo Brasil, além de três aterros no exterior, sendo eles localizados na Argentina, na Bolívia e no Peru.

A empresa trabalha com o tratamento de resíduos sólidos, líquidos e gás, e entrou em operação efetiva em 25 de junho de 2015, tendo seu funcionamento atrasado devido a questões sociais e políticas. As coletas recebidas são feitas diariamente, separadas em coletas pares (segunda, quarta e sexta-feira) e coletas ímpares (terça, quinta e sábado). O aterro recebe aproximadamente 40 mil toneladas de RSU por mês e Belém é responsável por $75 \%$ do total recebido.

A tonelada de resíduos sólidos custa $\mathrm{R} \$ 110$ para o setor privado e $\mathrm{R} \$$ 90,00 para os municípios de Belém e Ananindeua. Marituba não paga para depositar seus resíduos, em razão de um acordo estabelecido com a empresa pelo fato de o aterro estar localizado no município. 0 valor de alíquota de $5 \%$ do valor arrecadado mensalmente é pago em Imposto Sobre Serviço (ISS), imposto brasileiro municipal aplicado sobre competência do município pelos serviços prestados à empresa. No caso em tela, esse valor é pago ao município de Belém, por esse ser responsável pela fiscalização e regulação do aterro, e $5 \%$ de taxa de compensação ambiental é paga pelos possíveis danos ao meio ambiente ecologicamente equilibrado.

Em 2017, foram destinados para a Prefeitura de Belém mais

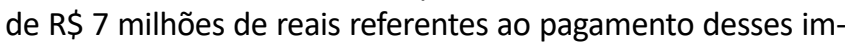
postos e de multas aplicadas pela Semas pelo funcionamento irregular na implementação do aterro em 2015. Por mês, a fatura do aterro é de $\mathrm{R} \$ \mathbf{2 . 5 0 0 . 0 0 0}$.
A GTR tem enfrentado problemas sociais, políticos e econômicos. A empresa funcionou durante um ano sem o tratamento para o chorume produzido no local, o que gerou problemas ambientais e revolta na população do município de Marituba, localizado na RMB, onde se localiza o aterro. A discussão que se iniciou no ano de implantação segue até os dias de hoje.

O fato de o aterro estar localizado na RMB é um problema que Dias (2012) debate. Segundo a autora, ninguém quer morar perto de um aterro sanitário por causa dos odores desagradáveis exalados, da contaminação de corpos d'água e do solo e do chorume produzido. Neste aterro, em Belém e toda a RMB, é um agravante devido ao elevado índice pluviométrico da região, às características climáticas locais e ao não tratamento de chorume, que geram danos significativos aos corpos hídricos próximos ao aterro, além de desconforto para a população.

São recebidas, em média, 1.200 toneladas diárias de resíduos no aterro, exceto às segundas e terças-feiras, nas quais essa média pode alcançar 1.700 toneladas, por consequência do total acumulado nos finais de semana. Nos períodos festivos, esse volume chega a 2.000 toneladas diárias, entre 180 e 200 caminhões circulando no aterro 24 horas por dia.

A GTR conta com impermeabilização contínua dos resíduos para evitar a contaminação do solo, cobertura das lagoas de pré-tratamento de chorume, em que são armazenados temporariamente o chorume a ser tradado, instalação de novas máquinas de osmose nas quais o chorume é tratado, instalação de queimadores para a transformação do metano em gás menos poluente e sistema de pulverizadores capazes de encapsular o cheiro no ar, minimizando a dispersão do odor.

O chorume é um líquido extremamente tóxico e danoso à saúde, formado pela infiltração da água da chuva no aterro. Se não tratado, pode contaminar o solo, o ar e os recursos hídricos (Conde et al., 2014). Após o processo de tratamento, o chorume fica disponível para uso nas dependências do aterro, sendo utilizado para lavar equipamentos, molhar o asfalto e até ser despejado nas redondezas do aterro.

Segundo os responsáveis, essa água não é mais tão prejudicial quanto o chorume propriamente dito, então pode ser despejada nos rios, na mata, mas em hipótese alguma pode ser consumida. É justamente o despejo ou o vazamento de chorume na região do município que mais acarreta problemas socioambientais e econômicos para o aterro.

O órgão responsável pela gestão dos RSU em Belém é a Sesan. De acordo com informações coletadas em entrevistas com seus representantes, o plano de gestão de resíduos do município está em desenvolvimento, e nele constarão as diretrizes de coleta seletiva e saneamento básico exigidas na PNRS. No entanto, apesar da inexistência do plano, a Prefeitura de Belém não deixa de agir ao tentar viabilizar a coleta 
seletiva e isso se dá por meio do Departamento de Resíduos Sólidos (Dres), o qual presta apoio à Associação dos Recicladores das Águas Lindas (Aral) e à Associação de Coleta Seletiva de Belém (ACCSB), que ficam dentro do único galpão de triagem de Belém, localizado no Canal São Joaquim, agindo conforme as diretrizes da PNRS.

Para os catadores não regularizados, a prefeitura fornece ajuda cedendo esporadicamente transporte para a coleta dos materiais recicláveis. Ela também trabalha com outra associação por meio de contrato, de modo que esta fique responsável pela coleta seletiva do bairro de Nazaré. Essa associação foi a única a vencer uma licitação publicada pela prefeitura, pois estava regularizada de acordo com o que foi exigido. Por receber um valor para a realização do serviço, ela não recebe nenhum outro apoio, como o fornecimento de transporte, motoristas, combustível, etc.

A partir das informações coletadas, para que Belém formule um plano integrado de gestão de resíduos, é necessário que seja feito um levantamento sobre a geração, o manejo e a disposição destes no município, para que o prognóstico referente a metas e ações a serem tomadas seja elaborado, minimizando os problemas referentes aos RSU. O fato da prefeitura auxiliar algumas associações e catadores de materiais recicláveis ainda não é suficiente para assegurar que a coleta seletiva esteja de fato sendo implementada, visto que o horizonte de associações às quais ela presta suporte é inferior à quantidade total de associações e/ou cooperativas de catadores de materiais recicláveis, que chega a cerca de 24 empreendimentos.

Sem um plano municipal, a gestão integrada de RSU não ocorrerá. Os problemas socioambientais e econômicos relacionados a esses resíduos não serão minimizados, fazendo, inclusive, com o que o município não arrecade recursos necessários para essa gestão.

Desta forma, tratando-se da gestão de RSU no município, no período de 2016 a 2018, os dados apontam que foram gastos $\mathrm{R} \$ 370.623 .752,02$ com coleta, transporte e disposição de resíduos, além da limpeza de ruas. No mesmo período, foram gastos $R \$ 143.079,00$ para viabilizar e estruturar o galpão de triagem localizado no lixão do Aurá, o qual até meados de 2015 recebia os resíduos produzidos em Belém e RMB, recebendo hoje apenas resíduos de construção civil. Entretanto, esse galpão, que recebe investimentos desde 2016, encontra-se desativado e não há previsão para sua ativação (Prefeitura de Belém, 2019). Verifica-se a discrepância de valores entre o manejo de resíduos e o quanto se gasta com infraestrutura para os catadores de materiais recicláveis, estrutura esta inutilizada.

Se houvesse uma gestão integrada eficiente, possivelmente esses valores seriam minimizados, pois todo o planejamento antecederia a tomada de decisões, priorizando a redução de custos e a inclusão dos catadores no processo de tomada de decisões, além de uma melhor realização do trabalho feito por esses trabalhadores, maximizando a utilidade dos recursos. Dessa forma, uma das alternativas para a solução e/ou a meIhora da questão dos RSU em Belém é a elaboração, o planejamento e a execução do PMGIRS.

Segundo Juliatto et al. (2011), um plano de gestão integrada faz parte da melhoria do desempenho ambiental na administração pública, envolvendo diversos setores públicos que, em suas atividades, são importantes agentes econômicos, pois são consumidores de bens e serviços, em suas diversas atividades, gerando impactos ambientais. Os autores explanam que a gestão integrada de resíduos envolve diferentes órgãos públicos e a sociedade civil, levando em consideração as características geográficas, demográficas, climáticas, culturais, econômicas, sociais, de geração e tipo de resíduos, que são as principais fontes geradoras e destinação dada a esses resíduos. O plano visa elevar a qualidade de vida da população e compreende ações normativas, operacionais, financeiras e de planejamento amplamente interligadas, além de comprometidas (Martins et al., 2017).

É nesse ponto que a gestão de resíduos em Belém apresenta falhas, visto que, apesar das ações voltadas à coleta seletiva, ao apoio dos catadores de materiais recicláveis, à limpeza urbana e à coleta dos resíduos, ainda não há um plano de gestão que integre toda a problemática ambiental, social e econômica ligada à geração de resíduos. Um ponto importante abordado na gestão integrada definida pela PNRS, art. 19 (Brasil, 2010), e pelo PEGIRS do Pará é o investimento na capacitação, na inclusão e na inserção social dos catadores de materiais recicláveis, bem como na prática da coleta seletiva.

É preciso inserir os catadores informais no processo e, para isso, o foco deve estar na separação da fonte dos resíduos para viabilizar a coleta seletiva, o que faz parte da diretriz de responsabilidade compartilhada e de programas de educação ambiental que podem ser implementados (Machado, 2012; Martins et al., 2017; Neves, 2013). Sendo assim, esses materiais devidamente segregados seriam encaminhados para os centros de triagem/apoio social.

Segundo o Ministério do Meio Ambiente (Brasil, [S.d.]), a coleta seletiva é a coleta diferenciada de materiais que foram separados previamente de acordo com a sua constituição ou composição. Ou seja, resíduos com características similares são selecionados pelo gerador (que pode ser o cidadão, uma empresa ou outra instituição) e disponibilizados para a coleta separadamente.

A coleta seletiva permite que haja maior preservação dos recursos naturais, já exauridos, além de diminuir os custos crescentes na obtenção de matéria-prima e podendo até economizar na produção de energia, já que materiais como o papel seriam reaproveitados. Além disso, pode diminuir os 
custos crescentes com a manutenção do aterro sanitário, visto que, com a quantidade de resíduos cada vez maior, este alcançará sua capacidade de funcionamento e como muitos dos materiais recicláveis demandam um período de tempo para se decompor, esse espaço ocupado por eles poderia ser preenchido por outros resíduos orgânicos ou quaisquer outros materiais não recicláveis, aumentando a vida útil do aterro.

Igualmente, contribui para a diminuição da poluição e a meIhora da saúde pública: a partir do momento em que mais material é reciclado, menos é despejado no meio ambiente. Além disso, pode gerar renda para aqueles que precisam, como é o caso dos catadores de resíduos sólidos estabelecidos em Belém e na RMB (Brasil, [S.d.]; Neves, 2013).

\section{CONCLUSÃO}

Ao tratar dos RSU no Brasil, é possível verificar que a criação da PNRS e a implementação dos planos gestores de resíduos sólidos nos níveis estadual e municipal são de extrema importância para uma gestão eficaz e colaborativa, a qual está condicionada pela distribuição de recursos financeiros da União. O foco da pesquisa discutida aqui foi abordar a gestão local de RSU no município de Belém (PA), no que diz respeito à ausência de um PMGIRS, considerando como a implantação do plano seria vantajosa para a gestão dos resíduos do município e de que forma a sua ausência prejudica essa gestão, na qual representa uma preocupação com o meio ambiente, a saúde pública, o ambiente social e econômico.

Sendo assim, a gestão de RSU em Belém ainda é deficiente devido à falta de um plano que abranja todos os municípios da RMB, não permitindo, assim, que a gestão seja feita de forma correta entre os entes estaduais e municipais, estando, portanto, em desacordo com a PNRS. Vale dizer que um dos problemas para a criação desse plano na RMB é a falta de um diagnóstico por parte da Prefeitura de Belém capaz de levantar todos os dados referentes à coleta seletiva, à geração de resíduos, entre outros itens que fazem parte da PNRS.

Por um lado, há muitos desafios a serem superados, que vão desde o investimento correto em materiais, espaço, apoio às cooperativas e associações de materiais recicláveis até o aumento da quantidade de recicláveis, além da redução do volume de resíduos gerados por meio de ações de educação ambiental. Por outro lado, os benefícios de uma gestão integrada de resíduos sólidos são muitos, como, por exemplo, os econômicos, pelo fato de por meio da coleta seletiva, menos resíduos recicláveis serem encaminhados para os aterros, otimizando a vida útil destes e diminuindo os altos custos para dispor os resíduos. É preciso considerar também os benefícios sociais, ao gerar renda àqueles que necessitam, ambientais e de saúde pública, ao fazer um tratamento adequado dos resíduos, diminuindo seu descarte irregular nas ruas.
A partir da PNRS e seu art. 19 (Brasil, 2010), fica explícito que os municípios devem implantar planos municipais de gestão de resíduos como uma tática de melhoria da gestão. Sua elaboração promove melhorias na coleta seletiva e na qualidade de vida dos catadores, sendo o PMGIRS uma ferramenta de gestão ambiental.

Por fim, propõe-se para trabalhos futuros uma análise das alterações vigentes na PNRS, do estado atual do planejamento do PMGIRS do município de Belém, bem como se há um prazo para que este seja implementado e em qual estado se encontra sua formulação. Como limitações do trabalho, foram encontradas dificuldades na obtenção de informações durante as entrevistas, além dos poucos dados disponíveis no portal da Prefeitura de Belém que exemplificassem os gastos tidos com os resíduos.

\section{REFERÊNCIAS}

Associação Brasileira de Empresas de Limpeza Pública e Resíduos Especiais - ABRELPE (2015), "Panorama dos Resíduos Sólidos no Brasil 2014", disponível em: http://abrelpe.org.br/ panorama/ (acesso em 17 dez. 2019).

Associação Brasileira de Empresas de Limpeza Pública e Resíduos Especiais - ABRELPE (2018), "Panorama dos Resíduos Sólidos no Brasil 2017", disponível em: http://abrelpe.org.br/ panorama/ (acesso em 17 dez. 2019).

Associação Brasileira de Empresas de Limpeza Pública e Resíduos Especiais - ABRELPE (2020), "Panorama dos Resíduos Sólidos no Brasil 2018-2019”, disponível em: http://abrelpe.org.br/ panorama/ (acesso em 06 fev. 2020).

Berticelli, R.; Korf, E. P. 2016. Diretrizes para elaboração de um plano municipal de gestão integrada de resíduos sólidos. Revista de Engenharia Civil IMED, 3, 10-24. Disponível em: https:// doi.org/10.18256/2358-6508/rec-imed.v3n1p19-24. Acesso em: 17 dez. 2019.

Brasil. 1981. Lei no 6.938, de 31 de agosto de 1981. Diário Oficial da União, 2 set. 1981. Disponível em: http://www.planalto. gov.br/ccivil_03/LEIS/L6938.htm (acesso em 17 dez. 2019).

Brasil. 1999. Lei no 9.795, de 27 de abril de 1999. Diário Oficial da União, 28 abr. 1999. Disponível em: http://www.planalto. gov.br/ccivil_03/leis/19795.htm (acesso em 17 dez. 2019).

Brasil. 2007. Lei no 11.445 , de 5 de janeiro de 2007. Diário Oficial da União, 08 jan. 2007. Disponível em: http://www. planalto.gov.br/ccivil_03/_ato2007-2010/2007/lei/l11445.htm (acesso em $17 \mathrm{dez}$. 2019).

Brasil. 2010. Lei no 12.305, de 2 de agosto de 2010. Diário Oficial da União, 03 ago. 2010. Disponível em: http://www. planalto.gov.br/ccivil_03/_ato2007-2010/2010/lei/l12305.htm (acesso em 17 dez. 2019).

Brasil. Ministério do Meio Ambiente. ([S.d.]). Coleta Seletiva. Disponível em: http://www.mma.gov.br/cidades-sustentaveis/ residuos-solidos/catadores-de-materiais-reciclaveis/reciclagem-e-reaproveitamento (acesso em $17 \mathrm{dez}$. 2019). 
Conde, T. T.; Stachiw, R.; Ferreira, E. 2014. Aterro sanitário como alternativa para a preservação ambiental. Revista Brasileira de Ciências da Amazônia, 3, 69-80. Disponível em: https://www. tratamentodeagua.com.br/artigo/aterro-sanitario-como-alternativa-para-a-preservacao-ambiental/ (acesso em $17 \mathrm{dez}$. 2019).

Costa, R. D. A.; Nobre, S. B.; Farias, M. E.; Lopes, P. T. C. 2018. Paradigmas da educação ambiental: análise das percepções e práticas de professores de uma rede pública de ensino. Revista Electrónica de Enseñanza de las Ciencias, 17, 248-262. Disponível em: http://reec.uvigo.es/volumenes/volumen17/ REEC_17_1_12_ex1078.pdf (acesso em 17 dez. 2019).

Creswell, J. W. 2010. Projeto de Pesquisa: métodos qualitativo, quantitativo e misto. Artmed, Porto Alegre.

Dias, S. G. 2012. O desafio da gestão de resíduos sólidos urbanos. GV-executivo, 11, 16-20. Disponível em: http://bibliotecadigital.fgv.br/ojs/index.php/gvexecutivo/article/viewFile/22776/21542 (acesso em 17 dez. 2019).

Estado do Pará. 2008. Decreto Estadual no 1.066, de 19 de junho de 2008. Diário Oficial do Estado do Pará, 20 jun. 2008. Disponível em: http://www.setur.pa.gov.br/sites/default/files/ pdf/decreto_1066_2008.pdf (acesso em 17 dez. 2019).

Estado do Pará. 2014. Plano de Gestão Integrada de Resíduos Sólidos do Estado do Pará (PEGIRS). Relatório Síntese, Vol. I, II. Belém: Secretaria Municipal de Meio Ambiente.

Freitas, W. R. S.; Jabbour, C. J. C. 2011. Utilizando estudo de caso(s) como estratégia de pesquisa qualitativa: boas práticas e sugestões. Revista Estudo \& Debate, 18. Disponível em: http://univates.br/revistas/index.php/estudoedebate/article/ view/560 (acesso em 17 dez. 2019).

IBGE. 2020. Cidades e Estados. Belém. Disponível em: https:// cidades.ibge.gov.br/brasil/pa/belem/panorama (acesso em 02 jul. 2020).

Jacobi, P. R.; Besen, G. R. 2011. Solid Waste Management in São Paulo: the challenges of sustainability. Estudos Avançados, 25, 135-158. http://dx.doi.org/10.1590/S010340142011000100010

Juliatto, D. L.; Calvo, M. J.; Cardoso, T. E. 2011. Gestão integrada de resíduos sólidos para instituições públicas de ensino superior. Revista Gestão Universitária na América Latina - GUAL, 4, 170-193. https://doi.org/10.5007/1983-4535.2011v4n3p170

Lima, J. P. C.; Antunes, M. T. P.; Mendonça Neto, O. R.; Peleias, I. R. 2012. Estudos de caso e sua aplicação: proposta de um es- quema teórico para pesquisas no campo da contabilidade. Revista de Contabilidade e Organizações, 6, 127-144. https://doi. org/10.11606/rco.v6i14.45403

Machado, P. A. L. 2012. Princípios da política nacional de resíduos sólidos. Revista do Tribunal Regional Federal da 1a Região, 24, 25-33. Disponível em: https://core.ac.uk/download/ pdf/16037203.pdf (acesso em 17 dez. 2019).

Martins, A. M.; Lorenzo, H. C.; Castro, M. C. A. A. 2017. Plano municipal de gestão integrada de resíduos sólidos no município de Araraquara-SP: formulação e implementação. Revista Brasileira Multidisciplinar, 20, 81-92. https://doi.org/10.25061/25272675/ReBraM/2017.v20i1.499

Neves, F. O. 2013. Gerenciamento de resíduos sólidos: problemas e perspectivas em Toledo-PR. Caminhos de Geografia, 14, 27-42. Disponível em: http://www.seer.ufu.br/index.php/caminhosdegeografia/article/view/16580 (acesso em 17 dez. 2019).

Oliveira, T. B.; Galvão Junior, A. C. G. 2016. O planejamento municipal na gestão dos resíduos sólidos urbanos e na organização da coleta seletiva. Revista Engenharia Sanitária e Ambiental, 21, 55-64. https://doi.org/10.1590/S141341520201600100155929.

Prefeitura de Belém. 2020. Portal da Transparência Belém. Disponível em: http://www.belem.pa.gov.br/transparencia/ (acesso em 17 dez. 2019).

Ribeiro, B. M. G.; Mendes, C. A. B. 2018. Avaliação de parâmetros na estimativa da geração de resíduos sólidos urbanos. Revista Brasileira de Planejamento e Desenvolvimento, 7, 422443. https://doi.org/10.3895/rbpd.v7n3.8652

Santiago, L. S.; Dias, S. M. F. 2012. Matriz de indicadores de sustentabilidade para a gestão de resíduos sólidos urbanos. Engenharia Sanitária e Ambiental, 17, 203-212. https://doi. org/10.1590/S1413-41522012000200010

Stake, R. E. 2011. Pesquisa qualitativa: estudando como as coisas funcionam. Penso, Porto Alegre.

Viveiros, E. P.; Miranda, M. G.; Novaes, A. M. P.; Avelar, K. E. S. 2015. Por uma nova ética ambiental. Engenharia Sanitária e Ambiental, 20, 331-336. https://doi.org/10.1590/S141341522015020000114401

Yin, R. K. 2015. Estudo de caso: planejamento e métodos. 5 ed. Bookman, Porto Alegre.

Recebido: 13 fev. 2020

Aprovado: 30 jun. 2020

DOI: 10.20985/1980-5160.2020.v15n2.1612

Como citar: Cardoso, E.L., Ferreira Filho, H.R., Santos, V.C.P., Ferreira, A.O. (2020). Gestão integrada de resíduos sólidos urbanos no município de Belém, Pará, Brasil: vantagens e desafios da sua implementação. Revista S\&G 15, 2, 93-102. https://revistasg.emnuvens.com.br/sg/article/view/1612 